\title{
Use of complementary and alternative medicine among adult with epilepsy - experiences from a single epilepsy center in Malaysia
}

\author{
May-Yi Koh ${ }^{1}$, Si-Bao Khor ${ }^{1}$, Kheng-Seang Lim ${ }^{1 *}$, Si-Lei Fong ${ }^{1}$, Wei-Zhen Low ${ }^{2}$, Li-Ling Yeap ${ }^{2}$ and \\ Chong-Tin Tan ${ }^{1}$ \\ ${ }^{1}$ Division of Neurology, Department of Medicine, Faculty of Medicine, University of Malaya, Kuala Lumpur, \\ Malaysia. \\ ${ }^{2}$ Department of Clinical Pharmacy and Pharmacy Practice, Faculty of Pharmacy, University of Malaya, Kuala \\ Lumpur, Malaysia.
}

*Correspondence: kslimum@gmail.com; Tel.: +60379492585

Received: 2 August 2021; Accepted: 4 October 2021; Published: 7 February 2022

Edited by: Zurina Hassan (Universiti Sains Malaysia, Malaysia)

Reviewed by: Muzaimi Mustapha (Universiti Sains Malaysia, Malaysia); Farooq Shaikh (Monash University, Malaysia)

https://doi.org/10.31117/neuroscirn.v5i1.109

\begin{abstract}
Complementary and alternative medicine (CAM) usage were reported in Europe, the United States of America and monoethnic Asian countries such as Korea and Taiwan. However, limited literature is available on the variability of CAM usage patterns among people with epilepsy (PWE) in a multi-racial country in particular Malaysia. This cross-sectional study assessed the prevalence, types, predictors and impact of CAM use among adult PWE and their adherence to antiepileptic drugs (AEDs) treatment.140 patients were recruited, with a median age of 37.5 (IQR,28.051.5) years, majority female, had secondary or lower education level, earn <USD1077 and seizure frequency of $<1$ per month. One quarter (25.7\%) used CAM for seizure control, of which $94.4 \%$ adhered to AEDs treatment while on CAM. Common CAM used were prayers, traditional herbal remedies, massage, and acupuncture. Only 33.3\% have discussed CAM usage with their physician. The main reason for CAM usage was patients' willingness to try other alternatives for seizure control. Although most patients had not used CAM, 20.2\% were receptive to using CAM as concomitant treatment. Buddhists were more open to CAM while Muslims uses CAM selectively and avoid amulets, acupuncture, chiropractic, Ayurveda, yoga, and reiki. Logistic regression analysis showed Buddhist's religion (OR,11.01), Muslims (OR,4.04), $\geq 1$ seizure per month $(O R, 3.85)$ and monthly income of $\geq$ USD1077 (OR,2.92) as the predictors for CMA usage. CAM use is common in Malaysia, especially among Buddhists and Muslims, with higher socio-economic status, and uncontrolled seizures. CAM is mostly used to complement but not in replacement of AEDs.
\end{abstract}

Keywords: Epilepsy; Complementary; Alternative Medicine; Adherence;

(C2022 by the Koh et al. for use and distribution according to the Creative Commons Attribution (CC BY-NC 4.0) license (https://creativecommons.org/licenses/by-nc/4.0/), which permits unrestricted non-commercial use, distribution, and reproduction in any medium, provided the original author and source are credited. 


\subsection{INTRODUCTION}

Epilepsy, a chronic illness with a point prevalence of active disease of 6.38 per 1000 persons, is one of the commonest neurological disorders worldwide (Fiest et al., 2017). Conventional treatment for epilepsy includes the use of anti-epileptic drugs (AEDs). In recent years, non-drug therapies for pharmaco-resistant epilepsy such as epilepsy surgery, implantable device or diet therapy have shown impressive results in some cases. Despite the various forms of treatment available, more than one-third of newly diagnosed PWE does not achieve seizure freedom (Chen et al., 2018). Thus, many patients have considered the use of complementary and alternative medicine (CAM) together with their AEDs (Clarke et al., 2015; Metcalfe et al., 2010).

CAM consist of a group of various medical and healthcare system, practices, and products that were not included as part of the available conventional treatment for diseases (National Center for Complementary and Integrative Health, July 2018). CAM is classified into four domains of practice which consist of mind-body medicine (meditation, prayer/spirituality, yoga), biologically-based practices (natural substances such as herbal remedies, dietary supplements), manipulative and body-based practices (chiropractic care and massage therapy), and energy medicine (acupuncture and "Reiki") (McElroy-Cox, 2009) . Despite limited literature on the effectiveness of CAM in achieving better seizure control, the use of CAM is common in the United States of America (42\%), Germany (65\%) and the United Kingdom (20\%), and there is an increasing trend (Samuels et al., 2008). Similarly in African and Asian countries, CAM has been frequently used as a primary method of healthcare (Farrukh et al., 2018; Jeong et al., 2016). However, the prevalence and types of CAM used in PWE differs between countries due to differences in cultural belief and the type of CAM available (Farrukh et al., 2018).

CAM is widely accepted among Asian populations but has its consequential effect on AEDs compliance and epilepsy management. Thus, many studies were performed to understand the use of CAM. In India, 32\% of PWE have used CAM for seizure control. Ayurvedic medicine is the most common, followed by homeopathy, either alone $(43 \%)$ or in combination (38\%) with other CAM therapies (Tandon et al., 2002). A Korean study reported herbal remedies as the most common form of CAM used followed by health food, folk remedies, acupuncture and spirituality (Kim et al., 2006). There were $49.1 \%$ of Taiwanese patients using CAM such as traditional medicine (51.5\%) and temple worship (48.0\%) to manage their epilepsy (Kuan et al., 2011). In the North American continent, CAM usage such as stress management, medical marijuana, vitamins and supplements were common among PWE (Liow et al., 2007; McConnell et al., 2014; Sirven et al., 2003). In the Middle East, traditional Arab and Islamic medicine (TAIM) were prominently used with popular forms of CAM therapies such as 'mind-body' type (incantations and fumigation) and biologically based (herbal concoctions) (Al Asmi et al., 2013; Mesraoua et al., 2021).

However, there might be ethnic and cultural variations in CAM usage in Malaysia, which may affect healthseeking behavior among PWE of different ethnicity to attain seizure freedom. To the best of our knowledge, studies investigating the pattern and impact of CAM usage among PWE, especially in multi-racial and multireligious Malaysia, are limited. In Malaysia, the three main ethnicities are Malays, followed by Chinese and Indians. The practices among the Chinese and Indians might be similar to the Chinese in Taiwan and Indians in India, but the Malays have different cultural and religious practices. Further research is warranted to determine the similarity and differences in the pattern of CAM usage as well as its consequential effect on AEDs adherence and disease management in various ethnic groups. Therefore, we aim to determine the prevalence, types, predictors and impact of CAM use among adult PWE in Malaysia and its cultural variation. This study also investigates the adherence to AEDs in those using CAM. The findings of this study may guide decisions on CAM usage in various ethnicities, ensure better adherence to epilepsy treatment and improve patient satisfaction during healthcare consultation.

\subsection{MATERIALS AND METHODS}

\subsection{Sample recruitment}

This is a cross-sectional study involving $140 \mathrm{PWE}$, age of 18 years and above, with a diagnosis of epilepsy certified by neurologists, were able to read in English or Bahasa Malaysia, were treated in an adult neurology clinic in University Malaya Medical Centre (UMMC). Those who refused or were unable to provide consent, or without a history of seizures were excluded. Patients were recruited from the clinic via convenient sampling. This study was approved by the University Malaya Medical Ethics Committee (MECID. No. 201910187928).

\subsection{Measures}

A questionnaire was developed based on available literature to assess the usage of CAM amongst PWE as 
part of their epilepsy management (Beattie et al., 2017; Chen et al., 2016; Durón et al., 2009; Quandt et al., 2009). The questionnaire was reviewed by a neurologist, two pharmacists and 10 patients, for its content validity, and modified accordingly. Informed consent was obtained prior to the study. Sociodemographic and clinical information were collected. Monthly income was divided by RM4,360 (USD1,077) based on the B40 (bottom $40 \%$ low-income population) line in Malaysia. The usage of CAM was assessed in 4 sections, included (1) the use of CAM, (2) category of CAM including mind-body practices (praying, wearing the amulet, music therapy, yoga), biologically based practices (traditional herbs, homeopathy and Ayurveda, ketogenic diet and vitamins and supplements) manipulative and body-based practices (chiropractic and massage) and energy medicine (reiki and acupuncture) (Chui et al., 2014; Farrukh et al., 2021), and its effectiveness (3) justification of CAM usage/nonusage, and (4) adherence towards conventional medications.

\subsection{Statistical analysis and sample size calculation}

Statistical analysis using $I B M^{\circledR}$ SPSS ${ }^{\circledR}$ Statistics software (version 25.0) was performed with a significance level defined at 0.05 . The sample size was calculated was performed using OpenEpi (Dean et al., 2013), Version 3, an open-source statistical software package. We used the lowest prevalence of $30 \%$ reported in other studies, and a population of 200 in our epilepsy cohort, with a confidence interval set at 95\%. A minimum of 124 samples is needed in this study. Shapiro-Wilk test was used to identify the median age in years. Pearson's chisquare test $(\chi 2)$ was used to analyze categorical variables. Predictors of CAM use were ascertained with multivariate logistic regression. A two-tailed $p$-value of less than 0.05 was considered significant for the univariate analysis for variables which were then entered into the final models of logistic regression.

\subsection{RESULTS}

A total of 140 out of 165 patients completed the survey in this study, with a respondent rate of $84.8 \%$. The median age was 37.5 [IQR, 28.0-51.5] years, and $50.7 \%$ were female. The majority were Chinese $(50.7 \%)$, Buddhist $(40.7 \%)$, with a secondary or lower level of education (63.6\%), and with a monthly income of less than RM4,360 (USD1,077, 72.1\%). The median age of seizure onset was 17.5 [IQR, 7.0-30.0] years. The majority had less than one seizure attack per month (47.1\%). One hundred and thirty-four patients (95.7\%) were on AEDs with $71.6 \%$ reported AEDs to be effective in controlling their seizures. Another thirty-eight patients (28.4\%) agreed that AEDs has been only slightly effective or less in controlling their seizures. The median years of taking AEDs were 16.0 [IQR, 6.8-24.3]. (Table 1).

\subsection{Prevalence of CAM usage and adherence to AEDs regime as a treatment for epilepsy}

Thirty-six patients $(25.7 \%)$ have tried CAM for seizure control, of which the majority (94.4\%) continued their AEDs treatment while on CAM. Another $5.6 \%$ opted to discontinue their AEDs and fully transitioned to CAM as their epilepsy treatment. A majority of them (86.1\%) used CAM because they would try anything that would help to alleviate their condition (epilepsy), and some (8.3\%) were because of the side effects of AEDs. The majority tried CAM due to suggestions from a family member $(52.8 \%)$, followed by self-decision $(27.8 \%)$ or friends $(25.0 \%)$. Sources of CAM information include the personal accounts of family members $(41.7 \%)$ and friends $(33.3 \%)$, healthcare professionals such as doctors or pharmacists $(27.8 \%)$ as well as the internet (16.7\%).

Only 12 patients (33.3\%) have discussed the use of CAM with their healthcare service providers. One patient (2.8\%) stopped using AEDs in their treatment in the past month while another 2 (5.6\%) stopped in the past year. Half of the patients $(50.0 \%)$ continued CAM, even though $91.7 \%$ experienced side effects such as allergic reactions, vomiting, diarrhea and others while using it, specifically traditional herbal remedies. (Table 1)

\subsection{Justification of non-CAM usage as a treatment for epilepsy}

A majority of them have not tried CAM ( $n=104,73 \%$ ) with reasons such as believing in the effectiveness of conventional AEDs (56.7\%), inadequate CAM information (45.2\%) and doubts on the effectiveness of CAM in managing epilepsy (21.2\%). Twenty-one patients $(20.2 \%)$ were receptive to the idea of using CAM as a treatment for their epilepsy (Table 1).

\subsection{Prevalence and types of CAM usage}

The most common type of CAM used was praying (72.2\%) followed by traditional herbs (58.3\%), massage (58.3\%), and acupuncture (47.2\%). Half (50.0\%) who has tried praying agreed on its effectiveness in their seizure control, $27.8 \%$ in traditional herbs, and $41.7 \%$ in massage. However, about half (23.1-88.9\%) were unsure of the effectiveness of various types of CAM in seizure control. (Table 2) 
Table 1: Socio-demographic and clinical characteristics of the patients, and the usage of CAM and their reasons $(N=140)$.

\begin{tabular}{|c|c|c|}
\hline Variables & & Number of patients, $\mathrm{n}(\%)$ \\
\hline \multicolumn{3}{|c|}{ Sociodemographic Characteristics } \\
\hline \multirow[t]{2}{*}{ Gender } & Male & $69(49.3)$ \\
\hline & Female & $71(50.7)$ \\
\hline \multicolumn{2}{|l|}{ Median age* [IQR] } & $37.5[28.0-51.5]$ \\
\hline \multirow[t]{4}{*}{ Race } & Malay & $33(23.6)$ \\
\hline & Chinese & $71(50.7)$ \\
\hline & Indian & $34(24.3)$ \\
\hline & Others & $2(1.4)$ \\
\hline \multirow{3}{*}{ Religion } & Muslim & $35(25.0)$ \\
\hline & Buddhism & $57(40.7)$ \\
\hline & Others & $48(34.3)$ \\
\hline \multirow[t]{2}{*}{ Education level } & Secondary and below & $89(63.6)$ \\
\hline & Tertiary & $51(36.4)$ \\
\hline \multirow[t]{2}{*}{ Monthly income } & $<$ <M4360 (USD1077) & $101(72.1)$ \\
\hline & 2RM4360 (USD1077) & $39(27.9)$ \\
\hline \multicolumn{3}{|c|}{ Clinical Characteristics } \\
\hline \multicolumn{2}{|c|}{ Median of years of epilepsy diagnosis [IQR] } & $17.5[7.0-30.0]$ \\
\hline \multirow{5}{*}{$\begin{array}{l}\text { Number of } \\
\text { seizure attack } \\
\text { per MONTH }\end{array}$} & $<1$ & $66(47.1)$ \\
\hline & 1 to 5 & $48(34.3)$ \\
\hline & 6 to 10 & $11(7.9)$ \\
\hline & 11 to 15 & $7(5.0)$ \\
\hline & $\geq 16$ & $8(5.7)$ \\
\hline \multirow[t]{2}{*}{ Taking AEDs } & Yes & 134 (95.7) \\
\hline & No & $6(4.3)$ \\
\hline \multirow[t]{5}{*}{ Effectiveness of AEDs } & Very effective & $26(19.4)$ \\
\hline & Effective & $70(52.2)$ \\
\hline & Slightly effective & $25(18.7)$ \\
\hline & Not effective at all & $6(4.5)$ \\
\hline & Not sure & $7(5.2)$ \\
\hline \multicolumn{2}{|c|}{ Median years of taking AEDs [IQR] } & $16.0[6.8-24.3]$ \\
\hline \multicolumn{3}{|c|}{ Use of Complementary and Alternative Medicine (CAM) } \\
\hline \multirow[t]{2}{*}{ Tried CAM } & Yes & $36(25.7)$ \\
\hline & No & $104(74.3)$ \\
\hline \multicolumn{3}{|c|}{ Reasons for CAM use $(n=36)$} \\
\hline \multicolumn{3}{|c|}{ Are you still taking the AEDs prescribed by doctor after starting the CAM treatment? } \\
\hline Yes, continue & & $34(94.4)$ \\
\hline No, did not contin & & $2(5.6)$ \\
\hline
\end{tabular}

* Shapiro-Wilk test was used; ** Includes allergic reactions, vomiting, diarrhea and others secondary to traditional herbal remedies

\begin{tabular}{|c|c|c|}
\hline \multicolumn{2}{|l|}{ Variables } & Number of patients, $\mathrm{n}(\%)$ \\
\hline \multicolumn{3}{|c|}{ Why would you choose to try CAM that is not prescribed by doctor? } \\
\hline \multicolumn{2}{|l|}{ Side effects of AED } & $3(8.3)$ \\
\hline \multicolumn{2}{|l|}{ Worried effectiveness of AED } & $2(5.6)$ \\
\hline \multicolumn{2}{|c|}{ I will try anything that will help to alleviate my condition } & $31(86.1)$ \\
\hline \multicolumn{2}{|c|}{ The CAM treatment works for someone that I know } & $2(5.6)$ \\
\hline \multicolumn{2}{|l|}{ Others } & $1(2.8)$ \\
\hline \multirow[t]{5}{*}{ Person who suggests } & Family member & $19(52.8)$ \\
\hline & Friends & $9(25.0)$ \\
\hline & Doctor/Pharmacists & $4(11.1)$ \\
\hline & No one & $10(27.8)$ \\
\hline & Others & $1(2.8)$ \\
\hline \multirow[t]{7}{*}{ Way of obtaining info } & Family member & $15(41.7)$ \\
\hline & Friends & $12(33.3)$ \\
\hline & Doctor/Pharmacists & $10(27.8)$ \\
\hline & Internet & $6(16.7)$ \\
\hline & Newspaper/Magazine & $1(2.8)$ \\
\hline & Social Media & $2(5.6)$ \\
\hline & Others & $1(2.8)$ \\
\hline \multirow[t]{2}{*}{ Ever discuss with doctor about CAM } & Yes & $12(33.3)$ \\
\hline & No & $24(66.7)$ \\
\hline \multirow[t]{2}{*}{ Stopped AED for the past one MONTH } & Yes & $1(2.8)$ \\
\hline & No & $35(97.2)$ \\
\hline \multirow[t]{2}{*}{ Stopped AED for the past one YEAR } & Yes & $2(5.6)$ \\
\hline & No & $34(94.4)$ \\
\hline \multirow[t]{2}{*}{ Side effects of CAM** } & Yes & $33(91.7)$ \\
\hline & No & $3(8.3)$ \\
\hline \multirow[t]{3}{*}{ Continue CAM } & Yes & $18(50.0)$ \\
\hline & No & $9(25.0)$ \\
\hline & Not sure & $8(25.0)$ \\
\hline \multicolumn{3}{|c|}{ Reasons for not using CAM ( $n=104)$} \\
\hline \multicolumn{3}{|c|}{ What is the possible reason/s you are not using any CAM treatment? } \\
\hline \multicolumn{2}{|c|}{ I believe in the effectiveness of conventional AEDs } & $59(56.7)$ \\
\hline \multicolumn{2}{|c|}{$\begin{array}{l}\text { I do not have much information regarding CAM treatment } \\
\text { available }\end{array}$} & $47(45.2)$ \\
\hline \multicolumn{2}{|c|}{$\begin{array}{l}\text { I doubt the effectiveness of CAM treatment in managing } \\
\text { my condition }\end{array}$} & $22(21.2)$ \\
\hline \multicolumn{2}{|l|}{ Others; Never considered } & $2(1.92)$ \\
\hline \multicolumn{3}{|c|}{$\begin{array}{l}\text { If you are new to CAM treatment, will you consider to start using CAM } \\
\text { treatment to help in managing your epilepsy condition? }\end{array}$} \\
\hline & Yes & $21(20.2)$ \\
\hline & No & 49 (47.1) \\
\hline & Not sure & $34(32.7)$ \\
\hline
\end{tabular}

NEUROSCIENCE RESEARCH NOTES | 2022 | VOLUME 5 | ISSUE 1 | ARTICLE 109 | PAGE 4 
Table 2: Prevalence and types of CAM used ( $N=36)$

\begin{tabular}{|c|c|c|c|c|c|}
\hline \multirow{2}{*}{$\begin{array}{l}\text { Category of CAM, } \\
(n, \%)\end{array}$} & \multicolumn{5}{|c|}{ Effectiveness of CAM used, $N$ (\%) } \\
\hline & Not sure & Not effective at all & Slightly effective & Effective & Very effective \\
\hline \multicolumn{6}{|l|}{ Mind-body practice } \\
\hline Praying $(26,72.2 \%)$ & $6(23.1)$ & $2(7.7)$ & $7(26.9)$ & $6(23.1)$ & $5(19.2)$ \\
\hline Wearing amulet $(13,36.1 \%)$ & $7(53.8)$ & $2(15.4)$ & $2(15.4)$ & $2(15.4)$ & - \\
\hline Music therapy $(11,30.6 \%)$ & $5(45.4)$ & - & $2(18.2)$ & $2(18.2)$ & $2(18.2)$ \\
\hline Yoga $(11,30.6 \%)$ & $9(81.8)$ & - & $1(9.1)$ & $1(9.1)$ & - \\
\hline \multicolumn{6}{|l|}{ Biologically based Practices } \\
\hline Traditional herbs $(21,58.3 \%)$ & $6(28.5)$ & $5(23.8)$ & $8(38.1)$ & $1(4.8)$ & $1(4.8)$ \\
\hline Homeopathy $(13,36.1 \%)$ & $8(61.5)$ & $1(7.7)$ & $4(30.8)$ & - & - \\
\hline Ketogenic diet $(13,36.1 \%)$ & $7(19.4)$ & - & $2(5.6)$ & $4(11.1)$ & - \\
\hline $\begin{array}{l}\text { Vitamins and Supplements (12, } \\
33.3 \%)\end{array}$ & $2(16.7)$ & $2(16.7)$ & $5(41.6)$ & $1(8.3)$ & $2(16.7)$ \\
\hline Ayurveda $(9,25.0 \%)$ & $8(88.9)$ & - & $1(11.1)$ & - & - \\
\hline \multicolumn{6}{|c|}{ Manipulative and body-based Practices } \\
\hline Massage $(21,58.3 \%)$ & $6(28.5)$ & - & $10(47.6)$ & $4(19.1)$ & $1(4.8)$ \\
\hline Chiropractic $(9,25.0 \%)$ & $8(88.9)$ & 1 (11.1) & - & - & - \\
\hline \multicolumn{6}{|l|}{ Energy medicine } \\
\hline Acupuncture $(17,47.2 \%)$ & $7(41.1)$ & $6(35.3)$ & $2(11.8)$ & $2(11.8)$ & - \\
\hline $\begin{array}{l}\text { Energy healing (Reiki) (10, } \\
27.8 \%)\end{array}$ & $8(80.0)$ & $1(10.0)$ & $1(10.0)$ & - & - \\
\hline
\end{tabular}

Table 3: Comparison of socio-demographic and clinical characteristics between CAM users ( $N=36)$ and non-CAM users ( $N=104)$

\begin{tabular}{|c|c|c|c|c|}
\hline \multicolumn{2}{|c|}{ Variables } & \multirow{3}{*}{$\begin{array}{c}\begin{array}{c}\text { Patient using CAM } \\
\text { (n=36), } \mathbf{n}(\%)\end{array} \\
18(26.1) \\
18(25.4)\end{array}$} & \multirow{3}{*}{$\begin{array}{c}\text { Patient not using CAM } \\
\text { (n=104), } n(\%)\end{array}$} & \multirow{3}{*}{$\frac{p \text {-value }}{1.00}$} \\
\hline Gender & Male & & & \\
\hline & Female & & & \\
\hline \multicolumn{2}{|c|}{ Median age [IQR] $^{\mathrm{n}}$} & $31.00[24.50-41.00]$ & $39.50[30.00-53.75]$ & 0.01 \\
\hline \multirow[t]{4}{*}{ Race } & Malay & $10(30.3)$ & $23(69.7)$ & 0.14 \\
\hline & Chinese & $22(31.0)$ & $49(69.0)$ & \\
\hline & Indian & $4(11.8)$ & $30(88.2)$ & \\
\hline & Others & $0(0.0)$ & $2(100.0)$ & \\
\hline \multirow[t]{3}{*}{ Religion } & Muslim & $10(28.6)$ & $25(71.4)$ & 0.00 \\
\hline & Buddhism & $22(38.6)$ & 35 (61.4) & \\
\hline & Others & $4(8.3)$ & 44 (91.7) & \\
\hline \multicolumn{5}{|c|}{ Education level } \\
\hline & Secondary and below & $16(18.0)$ & $73(82.0)$ & 0.01 \\
\hline & Tertiary & $20(39.2)$ & $31(60.8)$ & \\
\hline \multicolumn{5}{|c|}{ Monthly income } \\
\hline & $<$ RM4360 (USD1077) & $17(16.8)$ & $84(83.2)$ & 0.00 \\
\hline & $\geq$ RM4360 (USD1077) & 19 (48.7) & $20(51.3)$ & \\
\hline Median c & years of diagnosis [IQR] ${ }^{n}$ & $18.50[10.50-27.50]$ & $16.50[6.25-30.00]$ & 0.52 \\
\hline \multicolumn{5}{|c|}{ Number of seizure attack per month } \\
\hline & $<1$ & $11(16.7)$ & $55(83.3)$ & 0.03 \\
\hline & $\geq 1$ & $25(33.8)$ & $49(66.2)$ & \\
\hline
\end{tabular}

${ }^{\mathrm{n}}$ Analysis using Mann-Whitney $\mathrm{U}$ test 


\subsection{Socio-demographic and clinical characteristics of CAM users}

Patients using CAM had a younger median age $(31.00$ years [IQR, 24.50-41.00] vs. 39.50 [30.00 -53.75] in those not using CAM, $p=0.01$ ), higher monthly income ( $48.7 \%$ vs. $16.8 \%$ in those with lower income, $p<0.001$ ), and education level $(39.2 \%$ vs. $18.0 \%$ in those with lower education level, $p=0.01$ ). A subanalysis correlating the category of CAM used and education level showed that those with higher education level have a higher tendency to use biologically based, manipulative and body-based practice, energy medicine, and yoga $(p<0.05)$. (Table S1) Those with Muslim (28.6\%) and Buddhist (38.6\%) faith used CAM more than others $(p<0.001)$. Patients with higher seizure frequency were more likely to use CAM (33.8\% vs. $16.7 \%$ in those with $<1$ seizure per month, $p=0.03$ ). (Table 3 )

\subsection{Religious variation in CAM usage}

Prayers were the most common form of CAM used among the Buddhist community followed by traditional medicine, similar to that of the Muslim community. Acupuncture was used more frequently among the Buddhists (22.8\%), compared to Muslims (2.9\%) and other religious groups $(6.3 \%, p<0.01)$. The practice of wearing an amulet was predominantly found among the Buddhism community (17.5\%) but less among those with Muslim religion $(2.9 \%, p<0.05)$. Yoga, reiki, Ayurveda, and chiropractic treatment were not used by the Muslims in this study. (Table 4)

\subsection{Predictive factors influencing CAM usage}

A binary logistic regression analysis was conducted to investigate the predictors of CAM usage. The full model with all predictors was statistically significant, $\chi 2(7$, $\mathrm{N}=140)=41.62, \mathrm{p}<0.001$. The model correctly classified $83.6 \%$ of cases. The strongest predictors for CAM usage were Buddhism religion (OR 11.01, 95\% $\mathrm{Cl} 3.00-40.42$, $p<0.001$ ), followed by Muslim religion (OR $4.04,95 \% \mathrm{Cl}$ 1.04-15.77, $p=0.04$ ), $\geq 1$ seizure attack per month (OR $3.85,95 \% \mathrm{Cl} 1.45-10.25, p=0.01)$ and monthly income of ZUSD1,077 (OR 2.92, 95\% Cl 1.10-7.75, $p=0.03$ ). (Table 5)

\subsection{DISCUSSION}

CAM was used in $25.7 \%$ of the adult PWE in our study, comparable to the Singaporean population (Chen et al., 2016). Majority of patients $(94.4 \%)$ adhered to their conventional AEDs treatment while using CAM. Similar to other studies, only a third of PWE using CAM reported the use to their healthcare service providers (Lim et al., 2005; Samuels et al., 2008). The reluctance to disclose the use of CAM leads to difficulty in detecting the CAM-drug interactions and their potential side effects. The possible reasons to not disclose their CAM use was hypothesized to be the fear of physician's disapproval on CAM usage, no inquiry about the use of CAM by the healthcare team, and the belief that CAM was safe and would not interfere with conventional treatment. The under-reporting of CAM use could be resolved with a proactive inquiry by their physicians.

\subsection{Types of CAM used}

Praying was the commonest form of CAM used by PWE, similar to other studies (Durón et al., 2009; issler et al., 2014; Liow et al., 2007; Tonekaboni et al., 2014). Despite the cultural differences in our multi-ethnic country, this was expected as daily prayers were common as part of our religious identity. Praying, as a form of spiritual healing would help patients to cope better with their epilepsy leading to an improved sense of well-being (issler et al., 2014).

Similarly, the traditional herb was another commonly used CAM found in our study (Canter \& Ernst, 2004; Kaufman et al., 2002) alongside homeopathy remedies, Ayurveda, vitamins and supplement in PWE. The safety of these traditional herbs remained a major concern to physicians as the quantity and quality of their exact active ingredients were unknown, leading to unpredictable herb-drug interaction. Conventional AEDs used to treat PWE were often prescribed with the expectation that it would act in a predictable and doserelated effect on seizure control. However, when herbal or homeopathy remedies were used before consulting with a physician, it acts as a variable that might affect the drug disposition. These remedies may contain physiologically active substances including AEDs, which when consumed with prescribed AEDs, may lead to AED toxicity (Garg et al., 1998; Lau et al., 2000; Özdemir et al., 1998; Yin et al., 2004). In addition, there were many reports on unsupervised herbal remedies contaminated with neurotoxic heavy metals such as lead and arsenic, which resulted in the lowered seizure threshold (Samuels et al., 2008; Saper et al., 2004). Other CAM forms used include acupuncture, ketogenic diet, yoga, prayers, energy healing (Reiki), and chiropractic (McConnell et al., 2014; McElroy-Cox, 2009; Sirven et al., 2003).

\subsection{Reasons for CAM use}

While a majority of CAM users in our study used CAM intending to achieve better seizure control or to reduce AED's side effects, CAM users in Singapore were more 
likely to use it for maintenance of their health $(72 \%)$ than for treatment of illness (28\%) (Lim et al., 2005). In India, reasons for CAM usage were linked to dissatisfaction over the effectiveness of AEDs, its side effects and costs, the need for personal control over their healthcare decisions and philosophical confluence that were compatible with patient's values and beliefs
(Tandon et al., 2002). In the Middle East, CAM were considered as a therapeutic option by both PWE and physicians of the Iranian society but this was reported to be linked to cultural misbelieves as most did not achieve any benefit (Asadi-Poova \& Emami, 2014; AsadiPooya et al., 2019; Mesraoua et al., 2021).

Table 4: Religious variation in CAM used. ( $\mathrm{N}=140)$

\begin{tabular}{|c|c|c|c|c|}
\hline \multirow[b]{2}{*}{ Category of CAM (N) } & \multicolumn{3}{|c|}{ Religion } & \multirow[b]{2}{*}{$p$-value } \\
\hline & $\begin{array}{c}\text { Muslim } \\
(n=35,25.0 \%)\end{array}$ & $\begin{array}{c}\text { Buddhism ( } n=57 \\
40.7 \%)\end{array}$ & $\begin{array}{c}\text { Others } \\
(n=48,34.3 \%)\end{array}$ & \\
\hline \multicolumn{5}{|l|}{ Mind-body practice } \\
\hline Praying (26) & $8(22.9)$ & $15(26.3)$ & $3(6.3)$ & 0.023 \\
\hline Wearing amulet (13) & $1(2.9)$ & $10(17.5)$ & $2(4.2)$ & 0.020 \\
\hline Music therapy (11) & $1(2.9)$ & $7(12.3)$ & $3(6.3)$ & 0.232 \\
\hline Yoga (11) & $0(0.0)$ & $7(12.3)$ & $4(8.3)$ & 0.103 \\
\hline \multicolumn{5}{|l|}{ Biologically based Practices } \\
\hline Traditional herbs (21) & $5(14.3)$ & $13(22.8)$ & $3(6.3)$ & 0.060 \\
\hline Homeopathy (13) & $1(2.9)$ & $8(14.0)$ & $4(8.3)$ & 0.193 \\
\hline Ketogenic diet (13) & $1(2.9)$ & $9(15.8)$ & $3(6.3)$ & 0.078 \\
\hline Vitamins and Supplements (12) & $2(5.7)$ & $7(12.3)$ & $3(6.3)$ & 0.428 \\
\hline Ayurveda (9) & $0(0.0)$ & $6(10.5)$ & $3(6.3)$ & 0.135 \\
\hline \multicolumn{5}{|c|}{ Manipulative and body-based Practices } \\
\hline Massage (21) & $4(11.4)$ & $13(22.8)$ & $4(8.3)$ & 0.093 \\
\hline Chiropractic (9) & $0(0.0)$ & $7(12.3)$ & $2(4.2)$ & 0.048 \\
\hline \multicolumn{5}{|l|}{ Energy medicine } \\
\hline Acupuncture (17) & $1(2.9)$ & $13(22.8)$ & $3(6.3)$ & 0.005 \\
\hline Energy healing (Reiki) (10) & $0(0.0)$ & $7(12.3)$ & $3(6.3)$ & 0.081 \\
\hline
\end{tabular}

Table 5: Logistic regression model for predictors of CAM usage

\begin{tabular}{|c|c|c|c|c|c|c|c|c|}
\hline & \multirow{2}{*}{ B } & \multirow{2}{*}{ S.E. } & \multirow{2}{*}{ Wald } & \multirow{2}{*}{ df } & \multirow{2}{*}{ Sig. } & \multirow{2}{*}{$\operatorname{Exp}(B)$} & \multicolumn{2}{|c|}{ 95\% Cl for EXP(B) } \\
\hline & & & & & & & Lower & Upper \\
\hline Age & -.028 & .02 & 2.72 & 1 & .10 & .97 & .94 & 1.01 \\
\hline Religion: Buddhism & 2.40 & .66 & 13.07 & 1 & .00 & 11.01 & 3.00 & 40.42 \\
\hline Religion: Muslim & 1.40 & .70 & 4.04 & 1 & .04 & 4.04 & 1.04 & 15.77 \\
\hline Seizure attack per month: $\geq 1$ & 1.35 & .50 & 7.27 & 1 & .01 & 3.85 & 1.45 & 10.25 \\
\hline Monthly income: যUSD1077 & 1.07 & .50 & 4.65 & 1 & .03 & 2.92 & 1.10 & 7.75 \\
\hline Education level: Tertiary & .97 & .51 & 3.59 & 1 & .06 & 2.63 & .97 & 7.15 \\
\hline
\end{tabular}

The Moorish population believes that epilepsy was caused by excessive consumption of 'iguindi' and certain foods act as an antidote (Traore et al., 1998). In North Africa, the majority of PWE were treated by traditional healers long before consulting a medical doctor, because of illiteracy, financial limitations, and lack of neurologists (Kissani et al., 2021; Louhab et al., 2005). 
However, in Asia, CAM was not perceived to be superior or more effective than conventional medicine in general, and thus in our study majority use CAM concomitantly with their AEDs rather than replacing them (Lim et al., 2005). In Malaysia, CAM were also popularly used among the public for general health maintenance purpose, especially herbs (29.6\%) (Siti et al., 2009). This is because of the Asian medicine concept emphasizing the importance to achieve a healthy balance. However, the determination and expectation of CAM practice for a disease are much greater than for general health.

\subsection{CAM and perceived efficacy in seizure control}

Despite the emerging trend of CAM use among PWE, there has been limited evidence on the efficacy of CAM to achieve better seizure control. Studies from the USA, Taiwan and Korea reported varying results of selfmeasured seizure control while consuming CAM with no direct evidence on its efficacy (Kim et al., 2006; Kuan et al., 2011; McConnell et al., 2014). Many of the CAM modalities available may promote general well-being by improving sleep patterns, exercise and eating habits leading to an indirect reduction in seizure frequency (McConnell et al., 2014). Further trial studies on the efficacy of CAM were warranted to determine its efficacy in seizure control. In this study, about half of the CAM users agreed on the effectiveness of seizure control, but equally another half were unsure of its effectiveness. Despite lack of scientific evidence or certainty about the effectiveness, many people use CAM as an alternative or complementary therapy with the belief that CAM has no or minimal adverse effects, as shown in this study. In addition, most CAM practices health-seeking behaviors are influenced by the sociocultural background rather than scientific evidence. That explains the importance to determine the cultural variations in CAM practice.

\subsection{Decision to use CAM and its side effects}

The decision for CAM usage was influenced by family members followed by self-decision and advice from a friend, a result similarly echoed in a Turkish study (Goker et al., 2012). Patients especially those who receive personal advice from a trusted confidante tends to have more belief in the safety of CAM and were less likely to report its use with their physicians (Giveon et al., 2004; Samuels et al., 2008). In addition, they may not be aware of the potential side effects of CAM (Chen et al., 2016). In our study, half of our patients continued their CAM usage despite experienced side effects while using it. This may be due to patients' perception of CAM as natural and safe (Ezeome \& Anarado, 2007; Okoronkwo et al., 2014). This perception has encouraged patients with chronic diseases such as epilepsy to continue using CAM despite its effects. Future clinical trials should be conducted to determine the safety and possible side effects of CAM prospectively as in clinical trials.

\subsection{Predictors for CAM use}

Our finding of frequent seizures attacks leading to the use of CAM as a form of treatment was consistent with several studies (Bosak \& Słowik, 2019; Kim et al., 2006; Kuan et al., 2011). Most studies found that patients with a lower socio-economic level and less educated were more likely to use CAM due to the lack of epilepsy knowledge (Chen et al., 2016; Goker et al., 2012). On the contrary, our study showed that those with higher education and income were more likely to use CAM. In line with our findings, a Korean study also reported the association between high income and the use of CAM (Kim et al., 2006). These patients may be more wellresourced to try CAM alongside the conventional treatment and can afford to choose and take control over their health-related issues (Wiles \& Rosenberg, 2001). In our study, higher educated PWE used more biologically based, manipulative and body-based practice, energy medicine, and yoga, not the other mind-body practice. The use of CAM among the educated and affluent individuals was probably related to the broader dissemination of the CAM information via the internet and the modernization of CAM industry.

\subsection{Cultural variation and cross-cultural influence}

This study showed religious variation in the pattern of CAM usage among PWE but no ethnic difference. Malaysia exists as a harmonious multi-religious society with 3 main ethnic groups, where some of the CAM practices were related to religion. Generally, in the Malaysian context, Malays were all Muslims in faith. In contrast, the Chinese could embrace different religions such as Buddhism and Christianity, and Indians practice Hinduism, Christianity or other faiths.

Prayers were the most popular form of CAM used in our study as part of Muslims and Buddhist religious practice. In addition, although amulet wearing was commonly used for health reasons by the Buddhists, it was less frequently used as a medical treatment for Malaysian Muslims, contrary to other studies (Al Asmi et al., 2013; Asadi-Pooya \& Emami, 2014). Usage of amulet containing anything other than Qur'anic verses were considered forbidden in Islam, but items such as prayer 
beads were still used during prayers among a minority of Muslims. Less frequent use of acupuncture among the Muslims was likely due to religious reasons, and their preference was 'Hijama' also known as cupping therapy or recitation as stated in the Holy Qur'an ( $\underline{A}$ Asmi et al., 2013).

The Chinese in Malaysia were more open to CAM practised by other cultural groups, but not the Malay (Muslim) population. Chiropractic treatment, popular in the west and mostly used for mechanical disorders of the musculoskeletal system, is gradually gaining its popularity in Asia especially among the Chinese in Malaysia, similarly in Singapore (Lim et al., 2005). Ayurvedic medicine originated from India, and in Malaysia it was accepted by the Chinese Buddhists but not among the Muslims (Tandon et al., 2002). Likewise, yoga and reiki were also not practised by the Muslims.

\subsection{Implications}

While there is limited literature on the effectiveness of CAM on seizure control, patients were often encouraged to try CAM and accept its potential benefits due to its effectiveness in certain countries (AsadiPooya et al., 2019; Kim et al., 2006; Mesraoua et al., 2021). Studies in Korea (Kim et al., 2006) as well as the Middle East and North Africa (MENA) region (Mesraoua et al., 2021) reported reduced frequency in seizure attacks with CAM use while $55 \%$ of the neurologist in Iran believed that CAM would be helpful in treating epileptic seizures (Asadi-Pooya et al., 2019). Further research is warranted to establish the effectiveness and safety of CAM, with strict regulations to supervise the production of herbal remedies, vitamins and supplements to ensure safety especially among vulnerable groups such as PWE. Possible interactions between conventional AEDs therapy and these remedies should be further explored and established, especially for AEDs with narrow therapeutic windows. Patients with chronic illnesses, such as epilepsy could benefit from discussion with their healthcare service provider to make informed decisions on CAM usage.

\subsection{Limitations}

As this study was conducted in a tertiary hospital and predominantly Chinese and limited by small a sample size, the findings may not be representative of the rural communities and patients in primary health care facilities or the Malaysian population in general. Future studies involving a greater percentage of the Malay population is needed to represent the Malaysian multicultural background. The inclusion of the rural population should also be considered to determine the differences in CAM usage between urban and rural populations. Although a small percentage of our patients switched to the use of CAM as their main form of epilepsy treatment, a community-based survey would be able to capture patients who have completely abandoned the conventional healthcare services after CAM use. Despite these limitations, this present study has contributed to the understanding of CAM usage in multi-ethnic settings and help identify the patients' conceptions and attitudes towards the growing interest in CAM usage. Patients' cultural beliefs should be respected, and our goal should be to guide patients in making informed decisions on CAM usage. This will facilitate better adherence to therapeutic suggestions and improve patient satisfaction with their health care encounter.

\subsection{CONCLUSIONS}

CAM use is common in Malaysia, especially among those with Buddhism and Muslim religions, higher socio-economic status, and patients with uncontrolled seizures. Despite that, CAM is mostly used in addition to but not in replacement of AEDs. Besides cultural variation, there is a cross-cultural influence in CAM usage.

Supplementary Materials: Table S1: Comparison of CAM usage between those with higher and lower education level. $(\mathrm{N}=140)$ is available online.

Acknowledgements: We would like to acknowledge the University of Malaya Faculty of Medicine Postgraduate Scheme (FOMPSS) and Impact Oriented Interdisciplinary Research Grant (IIRG) Programme (IIRG003A-2020HWB).

Author Contributions: M.Y. obtained the data, performed the statistical analysis, interpreted the data, and drafted the manuscript. S.B. obtained the data, performed the statistical analysis and interpreted the data. K.S. designed the study, reviewed the study protocol, supervised the execution, and coordinated the data analysis plan. S.L. supervised the execution and interpreted the data. W.Z. designed the study, wrote the protocol and obtained data. L.L designed the study and reviewed the protocol. All authors reviewed, revised, and approved the manuscript.

Conflicts of Interest: The authors declare no conflict of interest. 


\section{References}

Al Asmi, A., Al Maniri, A., Al-Farsi, Y. M., Burke, D. T., Al Asfoor, F. M., Al Busaidi, I., . . Essa, M. M. (2013). Types and sociodemographic correlates of complementary and alternative medicine (CAM) use among people with epilepsy in Oman. Epilepsy \& Behavior, 29(2), 361-366. https://doi.org/https://doi.org/10.1016/j.yebeh.2013.07.022

Asadi-Pooya, A. A., \& Emami, M. (2014). Perception and use of complementary and alternative medicine among children and adults with epilepsy: the importance of the decision makers. Acta Medica Iranica, 153-157. https://doi.org/https://acta.tums.ac.ir/index.php/acta/article/view/4839

Asadi-Pooya, A. A., Homayoun, M., \& Sharifi, S. (2019). Complementary and integrative medicine in epilepsy: what patients and physicians perceive. Epilepsy \& Behavior, 101(Pt A), 106545. https://doi.org/10.1016/i.yebeh.2019.106545

Beattie, J. F., Thompson, M. D., Parks, P. H., Jacobs, R. Q., \& Goyal, M. (2017). Caregiver-reported religious beliefs and complementary and alternative medicine use among children admitted to an epilepsy monitoring unit. Epilepsy \& Behavior, 69, 139-146. https://doi.org/10.1016/j.yebeh.2017.01.026

Bosak, M., \& Słowik, A. (2019). Use of complementary and alternative medicine among adults with epilepsy in a university epilepsy clinic in Poland. Epilepsy \& Behavior, 98(Pt A), 40-44. https://doi.org/10.1016/j.yebeh.2019.06.004

Canter, P. H., \& Ernst, E. (2004). Herbal supplement use by persons aged over 50 years in Britain. Drugs \& aging, 21(9), 597605. https://doi.org/10.2165/00002512-200421090-00004

Chen, C., Chong, Y. J., Hie, S. L., Sultana, R., Lee, S. H. D., Chan, W. S. D., . . Cheong, H. H. (2016). Complementary and alternative medicines use among pediatric patients with epilepsy in a multiethnic community. Epilepsy \& Behavior, 60, 68-74. https://doi.org/10.1016/j.yebeh.2016.04.008

Chen, Z., Brodie, M. J., Liew, D., \& Kwan, P. (2018). Treatment Outcomes in Patients With Newly Diagnosed Epilepsy Treated With Established and New Antiepileptic Drugs: A 30-Year Longitudinal Cohort Study. JAMA neurology, 75(3), $279-286$. https://doi.org/10.1001/jamaneurol.2017.3949

Chui, P. L., Abdullah, K. L., Wong, L. P., \& Taib, N. A. (2014). Prayer-for-health and complementary alternative medicine use among Malaysian breast cancer patients during chemotherapy. BMC complementary and alternative medicine, 14(1), 425. https://doi.org/10.1186/1472-6882-14-425

Clarke, T. C., Black, L. I., Stussman, B. J., Barnes, P. M., \& Nahin, R. L. (2015). Trends in the use of complementary health approaches among adults: United States, 2002-2012. National Health Statistics Reports(79), 1. https://doi.org/https://www.ncbi.nlm.nih.gov/pmc/articles/PMC4573565/

Dean, A. G., Sullivan, K. M., \& Soe, M. M. (2013). OpenEpi: Open Source Epidemiologic Statistics for Public Health, version 3.01. https://doi.org/http://www.openepi.com/Menu/OE_Menu.htm

Durón, R. M., Medina, M. T., Nicolás, O., Varela, F. E., Ramírez, F., Battle, S. J., . . Holden, K. R. (2009). Adherence and complementary and alternative medicine use among Honduran people with epilepsy. Epilepsy \& Behavior, 14(4), 645650. https://doi.org/10.1016/j.yebeh.2009.01.022

Ezeome, E. R., \& Anarado, A. N. (2007). Use of complementary and alternative medicine by cancer patients at the University of Nigeria Teaching Hospital, Enugu, Nigeria. BMC Complementary and Alternative Medicine, 7(1), 28. https://doi.org/10.1186/1472-6882-7-28

Farrukh, M. J., Makmor-Bakry, M., Hatah, E., \& Jan, T. H. (2021). Impact of complementary and alternative medicines on antiepileptic medication adherence among epilepsy patients. BMC Complementary Medicine and Therapies, $21(1), 50$. https://doi.org/10.1186/s12906-021-03224-2

Farrukh, M. J., Makmor-Bakry, M., Hatah, E., \& Tan, H. J. (2018). Use of complementary and alternative medicine and adherence to antiepileptic drug therapy among epilepsy patients: a systematic review. Patient Preference And Adherence, 12, 2111. https://doi.org/10.2147/PPA.S179031

Fiest, K. M., Sauro, K. M., Wiebe, S., Patten, S. B., Kwon, C. S., Dykeman, J., . . . Jette, N. (2017). Prevalence and incidence of epilepsy: A systematic review and meta-analysis of international studies. Neurology, 88(3), 296-303. https://doi.org/10.1212/WNL.0000000000003509

Garg, S. K., Kumar, N., Bhargava, V. K., \& Prabhakar, S. K. (1998). Effect of grapefruit juice on carbamazepine bioavailability in patients with epilepsy. Clinical Pharmacology \& Therapeutics, 64(3), 286-288. https://doi.org/10.1016/S00099236(98)90177-1

Giveon, S. M., Liberman, N., Klang, S., \& Kahan, E. (2004). Are people who use "natural drugs" aware of their potentially harmful side effects and reporting to family physician? Patient Education and Counseling, 53(1), 5-11. https://doi.org/https://doi.org/10.1016/S0738-3991(03)00241-6

Goker, Z., Serin, H. M., Hesapcioglu, S., Cakir, M., \& Sonmez, F. M. (2012). Complementary and alternative medicine use in Turkish children with epilepsy. Complementary Therapies in Medicine, 20(6), 441-446. https://doi.org/10.1016/i.ctim.2012.07.006

İşler, A., Turan, F. D., Gözüm, S., \& Öncel, S. (2014). Complementary and alternative approaches used by parents of children with epilepsy on epilepsy management. Epilepsy \& Behavior, 32, 156-161.

https://doi.org/https://doi.org/10.1016/j.yebeh.2013.12.010 
Jeong, M. J., Lee, H. Y., Lim, J. H., \& Yun, Y. J. (2016). Current utilization and influencing factors of complementary and alternative medicine among children with neuropsychiatric disease: a cross-sectional survey in Korea. BMC Complementary and Alternative Medicine, 16(1), 91. https://doi.org/10.1186/s12906-016-1066-4

Kaufman, D. W., Kelly, J. P., Rosenberg, L., Anderson, T. E., \& Mitchell, A. A. (2002). Recent patterns of medication use in the ambulatory adult population of the United States: the Slone survey. JAMA, 287(3), 337-344. https://doi.org/10.1001/jama.287.3.337

Kim, I. J., Kang, J. K., \& Lee, S. A. (2006). Factors contributing to the use of complementary and alternative medicine by people with epilepsy. Epilepsy \& Behavior, 8(3), 620-624. https://doi.org/10.1016/j.yebeh.2006.01.020

Kissani, N., Cherkaoui Rhazouani, O., Souirti, Z., Khramaz, M., Meryem, C., Mebrouk, Y., \& Ouazzani, R. (2021). Epilepsy in Morocco: Realities, pitfalls and prospects. Epilepsia Open, 6(1), 13-21. https://doi.org/10.1002/epi4.12440

Kuan, Y. C., Yen, D. J., Yiu, C. H., Lin, Y. Y., Kwan, S. Y., Chen, C., . . Yu, H. Y. (2011). Treatment-seeking behavior of people with epilepsy in Taiwan: a preliminary study. Epilepsy \& Behavior, 22(2), 308-312. https://doi.org/10.1016/j.yebeh.2011.06.034

Lau, K., Lai, C., \& Chan, A. Y. (2000). Phenytoin poisoning after using Chinese proprietary medicines. Human \& experimental toxicology, 19(7), 385-386. https://doi.org/https://doi.org/10.1191/096032700678816115

Lim, M. K., Sadarangani, P., Chan, H., \& Heng, J. (2005). Complementary and alternative medicine use in multiracial Singapore. Complementary Therapies in Medicine, 13(1), 16-24. https://doi.org/10.1016/j.ctim.2004.11.002

Liow, K., Ablah, E., Nguyen, J. C., Sadler, T., Wolfe, D., Tran, K.-D., . . . Hoang, T. (2007). Pattern and frequency of use of complementary and alternative medicine among patients with epilepsy in the midwestern United States. Epilepsy \& Behavior, 10(4), 576-582. https://doi.org/10.1016/i.yebeh.2007.02.017

Louhab, N., Jafoui, M., Stoti, N., \& Kissani, N. (2005). Prospective evaluation of traditional practices for epilepsy patients of marrakech: p1157. Epilepsia, 46, 356-357.

https://doi.org/https://www.researchgate.net/publication/285136627_Prospective_evaluation_of traditional_practices for epileptic patients of Marrakech

McConnell, B. V., Applegate, M., Keniston, A., Kluger, B., \& Maa, E. H. (2014). Use of complementary and alternative medicine in an urban county hospital epilepsy clinic. Epilepsy \& Behavior, 34, 73-76. https://doi.org/10.1016/j.yebeh.2014.03.011

McElroy-Cox, C. (2009). Alternative approaches to epilepsy treatment. Current Neurology and Neuroscience Reports, 9(4), 313-318. https://doi.org/10.1007/s11910-009-0047-0

Mesraoua, B., Kissani, N., Deleu, D., Elsheikh, L., Ali, M., Melikyan, G., . . Asadi-Pooya, A. A. (2021). Complementary and alternative medicine (CAM) for epilepsy treatment in the Middle East and North Africa (MENA) region. Epilepsy Research, 170, 106538. https://doi.org/https://doi.org/10.1016/j.eplepsyres.2020.106538

Metcalfe, A., Williams, J., McChesney, J., Patten, S. B., \& Jetté, N. (2010). Use of complementary and alternative medicine by those with a chronic disease and the general population-results of a national population based survey. BMC Complementary and Alternative Medicine, 10(1), 58. https://doi.org/10.1186/1472-6882-10-58

National Center for Complementary and Integrative Health, N. C. C. I. H. (July 2018). Complementary, alternative, or integrative health: what's in a name? Retrieved 14-1-2021 from https://www.nccih.nih.gov/health/complementaryalternative-or-integrative-health-whats-in-a-name

Okoronkwo, I., Onyia-pat, J.-I., Okpala, P., Agbo, M.-A., \& Ndu, A. (2014). Patterns of complementary and alternative medicine use, perceived benefits, and adverse effects among adult users in Enugu urban, Southeast Nigeria. EvidenceBased Complementary and Alternative Medicine, 2014, 239372. https://doi.org/10.1155/2014/239372

Özdemir, M., Aktan, Y., Boydaĝ, B., Cingi, M., \& Musmul, A. (1998). Interaction between grapefruit juice and diazepam in humans. European Journal of Drug Metabolism and Pharmacokinetics, 23(1), 55-59. https://doi.org/10.1007/BF03189827

Quandt, S. A., Verhoef, M. J., Arcury, T. A., Lewith, G. T., Steinsbekk, A., Kristoffersen, A. E., ... Fønnebø, V. (2009). Development of an international questionnaire to measure use of complementary and alternative medicine (I-CAM-Q). The Jornal of Alternative and Complementary Medicine, 15(4), 331-339. https://doi.org/10.1089/acm.2008.0521

Samuels, N., Finkelstein, Y., Singer, S. R., \& Oberbaum, M. (2008). Herbal medicine and epilepsy: proconvulsive effects and interactions with antiepileptic drugs. Epilepsia, 49(3), 373-380. https://doi.org/10.1111/i.1528-1167.2007.01379.x

Saper, R. B., Kales, S. N., Paquin, J., Burns, M. J., Eisenberg, D. M., Davis, R. B., \& Phillips, R. S. (2004). Heavy metal content of ayurvedic herbal medicine products. JAMA, 292(23), 2868-2873. https://doi.org/10.1001/jama.292.23.2868

Sirven, J. I., Drazkowski, J. F., Zimmerman, R. S., Bortz, J. J., Shulman, D. L., \& Macleish, M. (2003). Complementary/alternative medicine for epilepsy in Arizona. Neurology, 61(4), 576-577. https://doi.org/10.1212/01.wnl.0000073541.08356.47

Siti, Z. M., Tahir, A., Farah, A. I., Fazlin, S. M., Sondi, S., Azman, A. H., . . Zaleha, W. C. (2009). Use of traditional and complementary medicine in Malaysia: a baseline study. Complementary Therapies $n$ Medicine, 17(5-6), $292-299$. https://doi.org/10.1016/j.ctim.2009.04.002 
Tandon, M., Prabhakar, S., \& Pandhi, P. (2002). Pattern of use of complementary/alternative medicine (CAM) in epileptic patients in a tertiary care hospital in India. Pharmacoepidemiology and Drug Safety, 11(6), 457-463.

https://doi.org/10.1002/pds.731

Tonekaboni, S. H., Jafari Naeini, S., Khajeh, A., Yaghini, O., Ghazavi, A., \& Abdollah Gorji, F. (2014). Use of complementary and alternative medicine for epileptic children in tehran: a cross-sectional study (2009-2011). Iranian Journal of Child Neurolgy, 8(1), 26-31. https://doi.org/https://doi.org/10.22037/ijcn.v8i1.5095

Traore, H., Diagana, M., Debrock, C., Ba, A., Alqad, B., \& Preux, P. M. (1998). [Sociocultural approach to epilepsy in Mauritania]. African Journal of Neurological Sciences, 58(4), 365-368. https://doi.org/10.4314/ajns.v20i1.7522 (Approche socioculturelle de l'epilepsie en Mauritanie.)

Wiles, J., \& Rosenberg, M. W. (2001). 'Gentle caring experience'. Seeking alternative health care in Canada. Health \& Place, 7(3), 209-224. https://doi.org/10.1016/s1353-8292(01)00011-9

Yin, O. Q., Tomlinson, B., Waye, M. M., Chow, A. H., \& Chow, M. S. (2004). Pharmacogenetics and herb-drug interactions: experience with Ginkgo biloba and omeprazole. Pharmacogenetics, 14(12), 841-850. https://doi.org/10.1097/00008571$\underline{200412000-00007}$ 